\title{
Use of the AHP Methodology in Vehicle Design Process Dynamics: Determination of the Most Effective Concept Phases for the New Automotive Product
}

\author{
Fuat Ali Paker1, Cem Alppay¹, Begüm Sertyeşilişik² \\ ${ }^{1}$ Industrial Design Department, Istanbul Technical University, Istanbul, Turkey \\ ${ }^{2}$ Architecture Department, Istanbul Technical University, Istanbul, Turkey \\ Email:pakerali@gmail.com
}

How to cite this paper: Paker, F.A., Alppay, C. and Sertyeşilişik, B. (2018) Use of the AHP Methodology in Vehicle Design Process Dynamics: Determination of the Most Effective Concept Phases for the New Automotive Product. Journal of Transportation Technologies, 8, 312-330. https://doi.org/10.4236/jtts.2018.84017

Received: August 31, 2018

Accepted: October 23, 2018

Published: October 26, 2018

Copyright $\odot 2018$ by authors and Scientific Research Publishing Inc. This work is licensed under the Creative Commons Attribution International License (CC BY 4.0).

http://creativecommons.org/licenses/by/4.0/

\begin{abstract}
The function of decision-making in the management of new product development and vehicle design activities is achieved by defining, constructing or evaluating the outcome-oriented, and most effective steps from the sub-steps that form this basic process. The choice of the sub-stages of the basic process or the decision of how to do a job gains importance in terms of the efficiency of the firm's activities. Therefore, the decision making function is one of the basic elements involved in the formation and development of the basic processes that can comply with the market dynamics of firms. With the new product being developed, the selection, the current editing or the evaluation of the steps that make up the vehicle design activities for the automotive industry companies that exist and compete in the market, bring about significant gains. In the manufacturing industry, the design of the vehicle determines the market spread, while the competitive conditions are driven by the new or improved product decision. In both cases, the automotive industry firms must know the stages of the most appropriate vehicle design in their own right, and the steps of forming new project dynamics must be devised in this direction. In this study, the result oriented activity of the current vehicle design phases used in the automotive industry companies is determined and the order of importance of the stages is listed. For this purpose, under the same conditions of competition (the same market, the same class vehicles develops and manufactures), 4 in the automotive firm administration, a total of 40 employees ( $4 \times 10$ process manager) with the vehicle design was evaluated by determining the effectiveness of the use of the stage. At this stage, analytic hierarchy methods applied to each of the phases are explored in practice in-
\end{abstract}


stead of the use of the significance level automotive company. Study of the vehicle design phase of the automotive industry: structure, process modifications or new project reveals the important values to be configured according to the size.

\section{Keywords}

AHP, Process Development, Automotive Industry, Vehicle Design Process

\section{Introduction}

Repeated transactions are increasing the managerial responsibilities of managers in the upper echelons day by day under the processes of firms' development, competition or uncertain and variable environmental conditions. The most favourable preference orientation of a manager in decision-making approach leads to the evaluation of more than one quantitative and qualitative factor together [1]. Within the decision directions of the firms, detailed synthesis sets are included under the information gathering, situation evaluation and analysis, and scientific approaches. Multi-step basic processes are planned, guided, or classified according to new project variables by determining the effect of each sub-step. The ability of automotive companies to compete with existing or potential competitors over new products can be achieved through the interaction of many design process variables [2] [3]. In the course of new product development processes, the current definition of these factors or the dynamic fiction is important. The fact that automotive industry companies can make correct and quick decisions and convert them into applications under defined processes provides important contributions to competition power [4] [5]. Under this approach, companies using up-to-date decision support methods can effectively use functional business processes under time factor. Vehicle design activities in the automotive industry constitute the early stages of the new product development process [6] [7] [8]. In the automotive industry, identifying the definition or co-operation of current vehicle design phases is an important step in evaluating these early creation processes. The effective use or editing of early stages, in addition to preventing the renovations in the subsequent project steps, increases the efficiency of the new product development process [6] [9] [10] [11]. Automotive firms continue to struggle for existence with vehicle design and production, in a severe competition environment with new product. However, these companies, which provide development and propagation in the market with new vehicle design, provide important gains under the current editing of the stages [11] [12] [13]. In this study, each sub-stage of product development process, current vehicle design stages and final new product, which are important in automotive industry companies, are evaluated by Analytical Hierarchy Method (AHP). 


\section{AHP Calculation Method}

New product development in the automotive industry creates profit-based processes of existence. Among the main activities, the use of some steps or the stage value can add value to the result-oriented structure of the automotive company processes. The automotive industry companies must make the most appropriate new product development phase in line with the project targets in order to provide the market development and spread in the vehicle class they are in. Automotive industry firms in extend market share and effective deployment their vehicles to ensure the class project goals to make the most appropriate product development phase. Within the vehicle design process of the automotive industry companies, the final new product can be determined by the Analytical Hierarchy Process (AHP) method, which creates the most impactful steps. From the fuzzy logic solutions, the AHP creates an easy-to-understand methodology in the decision-making or evaluation process, along with multidimensional qualitative and quantitative factors, result-oriented mathematical model combinations. AHP, developed by Saaty (1980), is a methodology that evaluates knowledge, experience, processes, personal thoughts and predictions with logic mathematical formulas [14] [15]. This mode of operational research is a widely used, fast and efficient method for solving multi-criteria decision-making problems frequently applied in practice and in scientific approaches. Because of these gains, the use of AHP varies: the choice of product design collaboration [16] [17] [18] [19] [20], the most appropriate product choice [21] [22] [23], the current process selection and implementation [24] [25] [26] [27] [28], applications [29] [30], technology selection [31] [32] [33] [34], investment decisions [35] [36] customer evaluation [37] [38], risk management [39], supplier selection [40] [41] [42] [43]. The AHP generates the result by evaluating the alternatives in a hierarchical structure at the level of main or sub-criteria and possible sub-criteria in the framework of the objective that creates the main problem. For mixed, difficult to understand or non-stereotyped problems, the result is a focused method and is based on three basic stages. The first phase is the significance hierarchy determination, the second stage is the sub criteria or alternative determination of superiority, the final step is logical and statistically consistencies in the sanity check flow of the coefficient in the AHP mathematical model. The use of the AHP method provides effective solutions in the selection or evaluation of process-oriented systems. All parts of the AHP structure form one with the other. In addition, each piece is dependent on each other, and how the ratio of each change leads to other factors can be followed clearly. The traceability or elasticity of the AHP tier structure provides observable phase values for the decision site. The main problem with more than one option is that the variables that make up the defined alternatives are weighted within the whole of the factorials, taking into account the gradual importance of the variables. AHP is the method of revealing the importance preference of each criterion or process within the whole, which constitutes each alternative in hierarchical structure, under observable 
stages. AHP method is based on the decision scale (5 Scale) benchmarking as reported in Table 1.

After the basic problem has been transformed into a gradual structure, each variable in this model is treated according to the degree of importance over the weight of 5 scale (Table 1) with each other. Under the scaling unit given in Table 1, each factor with integrated values forms a cross matrix with binary comparisons according to the significance matrix (Table 2) [14]. As a result each factor is based on the logic of the other variable accumulate endless levels of preference. Therefore, each factor has a single value within the whole. The " $W_{i} / W$ " expression used in the binary comparison matrices that define the "significance" of the " $P$ " factor from the " $j$ " variable in order to achieve " $W$ ". For example, if the scale is 5 , it means that the value of " $i$ " is 3 times higher than the " $"$ " factor. Another way to explain this situation is that the factor " $j$ " is expressed in the binary comparison matrix where the factor " $i$ " is $2 / 3$ significant [14]. The basis of the AHP calculation method is based on the determination of the ratio of the eigenvectors created by the binary comparison matrices to each other. The method used in the study, the eigenvector of each binary comparison matrix is positioned in the hierarchy, tested by Expert Choice (EC) software. In addition, each row value in binary comparisons was normalized by considering the consistency ratio and control over the whole cell average of the matrix structure was ensured. The computation of the consistency of the binary comparison matrix, which forms the core of the main structure, is based on the continuity condition. Consistency calculations of binary comparison matrices: the highest relative ratio occurs at " $\lambda \max$ " matrix level with " $n$ " equal value. To calculate the significance levels of the factors, the geometric mean of each horizontal column is the "row effect value". By normalizing the rows of the clustered binary comparison matrices, the "relative significance value" $(W)$ is calculated. The impact values of each line in the binary comparison matrices are multiplied by $W$ and the importance ratios of the second stage " $R 2$ " are calculated. The next step under the mathematical model is to divide the master cluster variables corresponding to

Table 1. AHP rating scale [14].

\begin{tabular}{|c|c|c|}
\hline $\begin{array}{c}\text { Level of } \\
\text { Importance }\end{array}$ & Definition & Interpretation \\
\hline 1 & Equally preferred & Two activities contribute equally to the objective \\
\hline 3 & Moderately & $\begin{array}{l}\text { Experience and judgment slightly favour one activity over } \\
\text { another }\end{array}$ \\
\hline 5 & Strongly & $\begin{array}{l}\text { Experience and judgment strongly or essentially favour one } \\
\text { activity over another }\end{array}$ \\
\hline 7 & Very strongly & $\begin{array}{l}\text { An activity is strongly favoured over another and its dominance } \\
\text { demonstrated in practice }\end{array}$ \\
\hline 9 & Extremely & $\begin{array}{l}\text { The evidence favouring one activity over another is of the highest } \\
\text { degree possible for affirmation }\end{array}$ \\
\hline $2,4,6,8, \ldots$ & $\begin{array}{l}\text { Intermediate } \\
\text { values }\end{array}$ & Used to represent a compromise between preferences listed above \\
\hline
\end{tabular}


Table 2. Formula of the binary comparison cross matrix and position within the mathematical model [14].

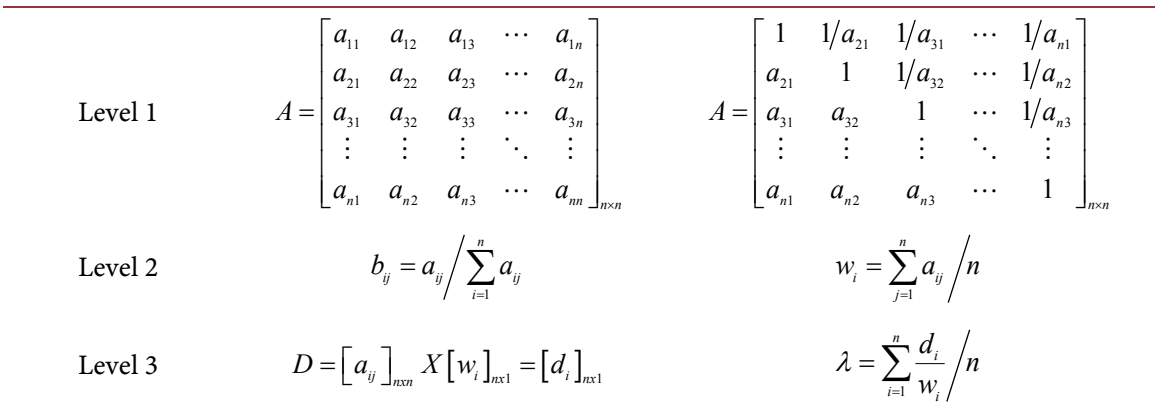

the obtained " $R 2$ " ratios, yielding the arithmetic mean of the third rank " $R 3$ " and the highest value " $\lambda \max$ " of the match. In all these stages, the consistency rate is determined at each stage and the deviations within the result are controlled. Within the calculations, the control of the consistency deviation value indicates that the installed system operates at the detail level. Hence, the definitions calculated under the binary comparison stages are consistent with the consistency of the final selection stage. In other words, one hundred percent consistency of consistency within the AHP method requires that the uncertainty over the variables be ignored. Therefore, in order to take into account possible risks, consistency must be under control. In Table 2, in the AHP binary comparison structure, the rate calculated by Saaty (1980) modelling method is used to check consistency [14].

In Table 2, the consistency ratio in the mathematical model is calculated by the structure of " $\lambda \max -n / n-1$ " (consistency ratio: consistency value/deviation ratio). Therefore, if the consistency ratio is less than or equal to 0.1 , the consistent output of the matrix value is assumed. In another approach, if this ratio is greater than 0.1, the matrix does not produce consistent results. Against this situation, the binary comparison rates that make up the selection need to be checked again. This study (Table 2), which is carried out under the AHP method, is calculated by the structural structure of the variables, which is formed by the impact importance levels. In the application section of the study, the calculation method of the AHP mathematical model is given in detail.

\section{Method of Determining Vehicle Design Stages}

The new product development process in automotive industry firms starts with vehicle design stages and results under manufacturing steps. Therefore, vehicle design activities consist of the basic stages of the formation, development and testing of the new product. The impact of these key phases on the new product has important implications for competitive automotive companies. With the new product processes, automotive companies create significant value creations such as market acquisition, development and spread under competition. Detailed research has been carried out on the equivalent products of the automotive companies that make up the definition and comparison structure of the vehicle 
design stages in the focal point of the study. In the same competitive environment, the working limit of the companies involved in both design and manufacturing was determined. Therefore, one-to-one interviews were conducted with 10 process managers from each automotive company included in the field survey. The fact that the company managers taking part in these interviews for at least 5 years, taking an active role in product development or design stages constitutes the final scope of the research. In addition, in the context of the conservation and confidentiality of ethical values, large automotive companies and managerial staff who were involved in the field survey were provided with study data under a specific code system. Automotive companies that emerged within the framework of the determined limits are divided into two classes, being dependent on local and international brands. This company classification is preferred for the formation of opposite data in the structure of comparison of in-depth information about the subject. The current vehicle design stages identified in the automotive companies within the scope of the research are given in Table 3. As it is explained in Table 4, the participant companies, which do not have some stages, carry out detailed plans to incorporate these works into their bodies. It has been determined that these companies, which do not have such stages, partially performed these processes in different defined steps. Therefore, the phase definitions and impact scores included in the evaluation structure are modelled under this perspective. As a result, each automotive company employee has determined the importance level of each vehicle design phase in terms of impact value on the new product (Table 3). As stated in Table 4, the vehicle design stage value given by each automotive company manager is formed under a 5 -scale arithmetic average value being created.

In Table 4, the vehicle design stages determined in the field work of the competing automotive companies (data such as testing of software, hardware, occupations and duration research data) were used. Therefore, for each stage in Table 4, each profession and every hardware or software use is evaluated under the study.

In Table 4, the basic phase definitions of software, hardware, occupation and similar features as determined in the design stages are evaluated by the employees in Table 4. 2D sketch; in the creation of new concepts, the drawing of the ideas through paper or computer (2D) interface, which includes the drawing works. This is the beginning phase of the project, in which creative values, new ideas or differences in the product become identifiable in the project objectives and competitive environment. $2 \mathrm{D}$ Technical view: drawing of the vehicle drawings from the sketch stage, according to the production and product structure, technical drawing standards. It is the basic step structure which includes the transformation of draft and idea works into manufacturing preparation. 2D Presentation: Draft and sketches are created with technical drawings expressed in the selection of vehicle alternatives to the top management. The approval process of the contents of the presentation prepared in computer or paper environment 
Table 3. Current vehicle design phases of automotive companies.

(a)

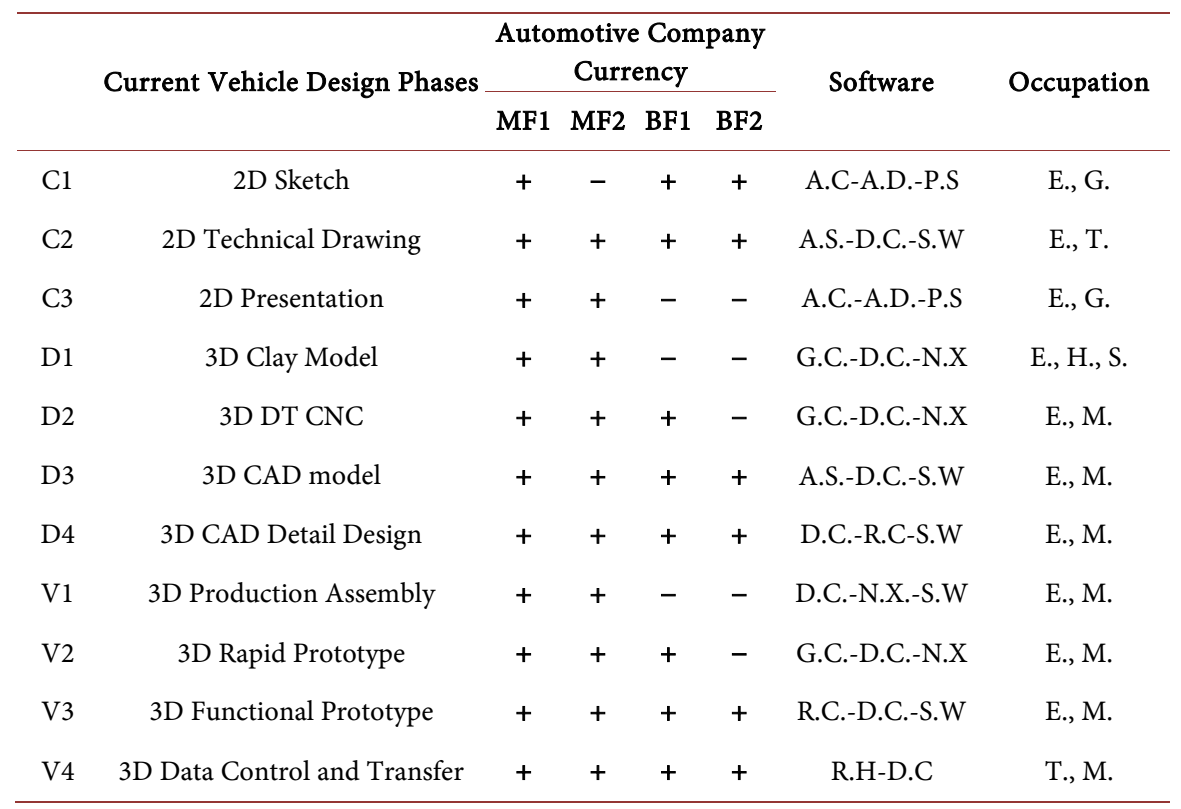

(b)

\begin{tabular}{cccccc}
\hline Abbrev & Software & Abbrev & Software & Abbrev & Occupation \\
\hline A.C. & Autodesk Alias Concept & N.X. & Unigraphics & E. & Industrial Designer \\
A.D. & Autodesk Alias Design & R.C. & Rhinoceros & T. & Draftsman \\
P.S. & Adobe Photoshop & G.C. & Cimatron & H. & Sculptor \\
A.S. & Autodesk Auto Studio & V.R. & VRay & G. & Grapher \\
D.C. & DassaultCatia & K.S. & Key Shot & S. & Ceramicist \\
S.W. & Dassault Solid Works & S.C. & Show Case & M. & Mechanical Engineer
\end{tabular}

Table 4. Effectiveness values of vehicle design stages at the level of automotive companies.

\begin{tabular}{ccccc}
\hline \multirow{2}{*}{ Current vehicle design phases } & \multicolumn{5}{c}{ The phase of impact value automotive companies } \\
\cline { 2 - 5 } & MF1 & MF2 & BF1 & BF2 \\
\hline 2D Sketch & 9 & 7 & 4 & 5 \\
2D Technical Drawing & 9 & 8 & 6 & 7 \\
2D Presentation and Approval & 8 & 5 & 9 & 7 \\
3D Clay Model & 9 & 4 & 8 & 6 \\
3D DT-CNC & 5 & 5 & 8 & 9 \\
3D CAD model & 9 & 6 & 3 & 1 \\
3D CAD Detail Design & 2 & 4 & 9 & 5 \\
3D Production Assembly & 9 & 7 & 4 & 1 \\
3D Rapid Prototype & 4 & 6 & 9 & 8 \\
3D Functional Prototype & 3 & 3 & 7 & 9 \\
3D Data Control and Transfer & 8 & 4 & 9 & 6 \\
\hline
\end{tabular}


to the senior management varies according to the automotive company. 3D Clay Model: It is the mass structure of the product, which physically identifies the vehicle model produced and selected with the use of clay mud (which is solidified at ambient temperature, formed at low temperatures) for automotive industry use. Within the scope of 2D sketches, under the support of technical drawings, it is the hand-made production of various scales, manufacture of the mud models. 3D DT \& CNC: The machine that converts the vehicle model formed from physical clay mud to the computer environment (physical objects, multi-axis, high-resolution photos under the computer coordinate system, point cloud forming, digital scanning device (DT)). The new model of the new vehicle formed by DT is the mathematical model (CAD) defined under the computer-aided three axis coordinate system. This stage creates conversions and modifications between the computer environment and the physical clay model. 3D model (defined under the triangular: $\mathrm{x}, \mathrm{y}, \mathrm{z}$, coordinate system) transported by DT, with the support of the CNC (numerically computerized milling machine in 3-axis or 5-axis coordinate system) takes the form of physical final product model. 3D CAD model: It is the working stage of CAD, which a whole is set of $3 \mathrm{D}$ data obtained after clay mud model manufacturing and $\mathrm{CNC}$ renovations. All of the information obtained from the previous stages, within the functional product structure, includes editing work. 3D CAD Detail: It is the process of defining the details required for each piece of CAD vehicle model to perform its usage functions in CAD environment. 3D CAD is defined in the vehicle model, the inner shell of each part of the outer shell, again in the virtual CAD environment is the stage of creation. 3D Mounting: This means that all parts of the $3 \mathrm{D}$ CAD vehicle model which is formed after the stage work up to this point, will be assembled in the serial production line. Nowadays, these new vehicle test installations are carried out under computer simulations. 3D Rapid prototype: is the modeless physical production technology, for the control of the functional use of new vehicle parts, which have been tested before the mass production, for the manufacturing and assembly trials. Although it is a new developing technology, it is completed in a very short time with the help of devices working in the computer environment. 3D Functional prototype: is the first trial installation phase of the parts of the new vehicle manufactured with serial production moulds. At the stage where the components of the whole constructions are performed in the process of adaptation and function, studies are carried out on the model for testing or certification of the new vehicle. The pre-production trial phase of the new vehicle runs all functions before mass production. 3D Data transfer: is the stage of sharing the $3 \mathrm{D}$ CAD data of the new vehicle with process stakeholders, whose conceptual formation, development and testing has been completed. It expresses the sharing of new vehicle information through $3 \mathrm{D}$ data by all process partners. In this step, the difference of the software used by each stage of the partners is the loss of CAD data.

The lower stages of each vehicle design activity as defined above consist of three basic stages according to the process flow. Along with the vehicle design 
phases defined as concept formation, development and testing, the operation of the lower stages constitutes a structure as given in Figure 1. In order to transform the hierarchical structure defined in Figure 1 into mathematical evaluation, the use of the steps in each automotive company or its significant impact on the new product was determined in the field studies (Table 4). The effect of each main and sub-process in Figure 1 on the use of automotive companies in the new product is evaluated over 9 points. For each process value to be modelled according to the AHP comparison scale, it is calculated under the new product effect rate of the other automotive firm value design stages over 9 system points. Example: The 3D virtual assembly stage is the most efficient vehicle design step for the MF1 automotive company, but the BF2 vehicle manufacturing has the lowest impact value for the same company.

In Figure 1, the main and sub-stages, the relative importance ratios of the comparison of automotive firms that make up the alternatives, have been tested by EC software. In addition, the effect of the stages, that constitute the vehicle design activities on the new product, in terms of the automotive companies in the alternatives, is calculated as, relative importance value. The results of the study, the relative significance and the consistency of the comparisons were tested by EC software.

\section{The Implementation of Findings}

For the phase definitions of vehicle design activities, the main automotive companies, including the application area, were visited. In this field study, it was determined that the definitions that emerged during the interviews with the company managers formed the effect value for the new product. Therefore, the total weight ratios and the effect of the phases of the main and sub-stages of each automotive company in the vehicle design activities on the new product have been determined. Also, in this study, as shown in Table 5, cross-matrices were formed by pairwise comparisons. In order to find the use and impact values of the sub-stage criteria of vehicle design within the automotive companies, the weight ratios of the consecutive main stages, which are defined as, Concept formation phase, Concept development phase, Concept testing phase alt, have been calculated. For this purpose, using the string in Table 2 based on the evaluations in Table 1, the main stage ratios were compared with each other, and the paired comparisons formed the cross-matrix results (Table 5). In Table 5, new product in the development process, the main phases of the most significant processes affecting the $46.6 \%$ compared to the value of "Design creation phase", and $20.4 \%$ relative significance at least developed vehicle impact value $(W)$ was determined with "Design verification phase". Using the comparison cross-matrices, for the purpose of determining the baseline effect values, with the determination of the relative significance, as described previously, the cross-matrices forming the double comparisons are normalized by calculating the largest eigenvector. EC software was used for the mentioned study. 


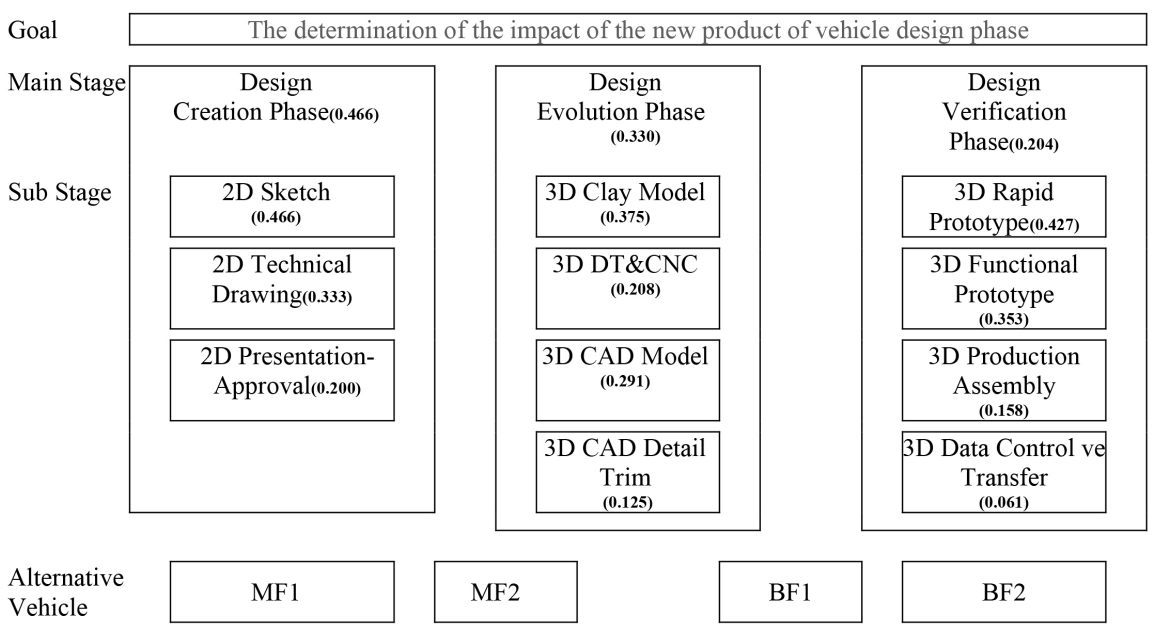

Figure 1. The model structure of the determination and effects of vehicle design stages on the new product by AHP method.

Table 5. Binary comparison of the fundamental vehicle design phase.

\begin{tabular}{ccccc}
\hline & $\begin{array}{c}\text { Design Evolution } \\
\text { Phase }\end{array}$ & $\begin{array}{c}\text { Design Verification } \\
\text { Phase }\end{array}$ & $\begin{array}{c}\text { Design Creation } \\
\text { Phase }\end{array}$ & $\begin{array}{c}\text { Relative Significance } \\
\text { Value }(W)\end{array}$ \\
\hline $\begin{array}{c}\text { Design Evolution } \\
\text { Design } \\
\text { Verification }\end{array}$ & 1 & $5 / 3$ & $5 / 7$ & 0.330 \\
Design Creation & $3 / 5$ & 1 & $3 / 7$ & 0.204 \\
& $7 / 5$ & $7 / 3$ & 1 & 0.466 \\
& & Consistency check=0.9<0 & \\
\hline
\end{tabular}

The test values obtained by the EC software were calculated by the cross-matrix ratios in Table 5 and the relative significance vector for the first stage of the problem was calculated. Therefore, for the solution of the sample problem at the level of automotive companies, it is revealed that the vehicle design phase that has the most effect on the new product is the concept of new formation phase with $46.6 \%$. This result is followed by the Concept development phase with $33 \%$ and Concept testing phase with $20.4 \%$ values. The consistency rate of the paired comparison matrices, which were created for the first level study of the problem tested with EC software, was calculated as $0.9 \%$. Since the consistency of the AHP mathematical model does not exceed 1\%, the cross-matrices have a valid comparison value. For the next step of the decision or selection model: The comparison of the sub-stages forming each basic phase, the evaluation rates defined in Table 5, and the sequence in Table 6, were compared with each other, and the comparison, cross-matrix calculations were tested under EC software (Tables 6-8). As a result of these calculations, it has been determined that the sub-stage of the 3D Data Transfer is $1.2 \%$ behind all the basic stages and the formation of the new product, is the least effective vehicle design step. In Table 6, the concept formation phase is calculated as the vehicle design phase with the highest impact value of the new product in the lower 
Table 6. The main processes "Design Creation Phase" of the binary comparisons lower sub-stages.

\begin{tabular}{ccccc}
\hline Design Creation Phase & 2D Sketch & 2D Technical Drawing & 2D Presentation & $W$ \\
\hline 2D Sketch & 1 & $7 / 5$ & $7 / 3$ & 0.466 \\
2D Technical Drawing & $5 / 7$ & 1 & $5 / 3$ & 0.333 \\
2D Presentation Approval & $3 / 7$ & $3 / 5$ & 1 & 0.200 \\
& \multicolumn{2}{c}{ Consistency check $=-1.779<0$} & &
\end{tabular}

Table 7. The main processes "Design Evolution Phase" of the binary comparisons lower sub-stages.

\begin{tabular}{|c|c|c|c|c|c|}
\hline $\begin{array}{c}\text { Design Evolution } \\
\text { Phase }\end{array}$ & 3D K Clay Model & $\begin{array}{c}\text { 3D } \\
\text { DT \& CNC }\end{array}$ & 3D CAD Model & $\begin{array}{c}\text { 3D CAD } \\
\text { Detail }\end{array}$ & $W$ \\
\hline 3D Clay Model & 1 & $9 / 5$ & $9 / 7$ & $9 / 3$ & 0.375 \\
\hline 3D DT \& CNC & $5 / 9$ & 1 & $5 / 7$ & $5 / 3$ & 0.208 \\
\hline 3D CAD Model & $7 / 9$ & $7 / 5$ & 1 & $7 / 3$ & 0.291 \\
\hline 3D CAD Detail Trim & $3 / 9$ & $3 / 5$ & $3 / 7$ & 1 & 0.125 \\
\hline \multicolumn{6}{|c|}{ Consistency check $=-1.1111<0$} \\
\hline
\end{tabular}

Table 8. The main processes "Design Verification Phase" of the binary comparisons lower sub-stages.

\begin{tabular}{cccccc}
\hline \multirow{2}{*}{ Design Verification Phase } & $\begin{array}{c}\text { 3D Rapid } \\
\text { Prototyp }\end{array}$ & $\begin{array}{c}\text { 3D Functional } \\
\text { Prototype }\end{array}$ & $\begin{array}{c}\text { 3D } \\
\text { Assembly }\end{array}$ & $\begin{array}{c}\text { 3D Data \& } \\
\text { Transfer }\end{array}$ & $W$ \\
\hline 3D Rapid Prototype & 1 & $7 / 5$ & $7 / 3$ & 7 & 0.427 \\
3D Functional Prototype & $5 / 7$ & 1 & 3 & 5 & 0.353 \\
3D Production Assembly & $3 / 7$ & $1 / 3$ & 1 & 3 & 0.158 \\
3D Data Control \& Transfer & $1 / 7$ & $1 / 5$ & $1 / 3$ & 1 & 0.061 \\
& Consistency check $=-1.106<0$ & & \\
\hline
\end{tabular}

stages of the basic process, with a ratio of $21.7 \%$ of the 2D Sketch step. Although the ratio of the sub-stages of the first sub-process of $2 \mathrm{D}$ sub-sketch (0.466) and 3D Rapid prototype (0.427) seems to be close within the AHP mathematical model, the effect values of the new product are positioned in the 1st and 8th positions. Among the sub-stages that make up the conceptual development phase, the position of the "3D clay model" in the impact order of importance constitutes the highest variability in the analysis. In Table 8, 3D Rapid Prototype and 3D Functional Prototype stages, in 6th and 7th places, provides the highest impact to the new product, among the sub-stages of the concept testing phase. In addition, other "design verification phase", testing of the sub stage "3D Production Assembly" and "3D Data Control \& Transfer" phases of new product impact ranking at the status of 10 and 11, led to the lowest position of the weight rate values. 2D Sketch and 2D Technical Views lam sub-stages within the basic process of Concept formation phase in Table 6, constitute the highest vehicle 
design steps affecting the new product with their 1st and 2nd position according to the calculations. Another sub-phase in the conceptual formation phase, $2 \mathrm{D}$ Presentation approval, is ranked 5th with the new product impact value. Finally, in Table 7, 3D Clay Model and 3D CAD Model vehicle design steps, which provide the highest potential impact to the new product, constitute the 3rd and 4th ranking position among the lower stages of the "concept development phase" basic process. However, the 8th and 9th positions of the other 3D DT \& CNC and 3D CAD detailing sub-stages forming the concept development phase in the new product impact order produced the lowest weight ratios of the study. In the study, the paired comparisons of the main and sub-stages calculated at the beginning level constitute the total composite relative importance ratios according to the results of the double comparison of the stage utilization values in the next step. Thus, in the AHP model generated in Figure 1, the weight ratios of the basic stages are calculated in Tables 5-7.

Tables 8-10 were combined on the basis of relative significance values $(W)$ basic stages and lower stages (Table 11, Table 12).

Measurement of the impact new product under the vehicle design process for each main-phase and every sub-stage, of the determination relative significance values rates. The value in fundamental problem on the determination of the appendix includes the following formulas (Table 13). According to the model of resources in research on analytic hierarchy method describes the stages of the appendix [14] [15] [27] [44] [45] [46] [47]. Among the factors in all levels of the analytic hierarchy model of " $I=1,2,3, \cdots, n$ and $j=1,2,3, \cdots, n$ " depiction " $n$ $\times n$ " level, the first stage of the calculation of comparative cross-matrices. Table 13 , the non-clustered indexes defined in the formula A1 column contained in A matrix. All diagonal values of the matrix A (Table 13: 1B column), question 1. Therefore, in the case of " $I=j$ " equality gives the result of " $a_{i j}=1$ ". In addition, A matrix is symmetric elements in themselves non-uniformity each other raises the status of irreversible equality. Therefore, this equality " $a_{i j}=1 / a_{j i}$ " is expressed in the form. In this context, the state of A matrix question Table 13, 1B expressed with the formula in the column. In the case of equality in question contained a criteria, the relative significance rate in terms of the effect of the solution and how each alternative, within the framework of research strengths, or

Table 9. The "Design Creation Sub-Phase" of new product impact value $(W)$ alternative vehicles.

\begin{tabular}{cccc}
\hline \multicolumn{3}{c}{ Design Creation Phase (0.466) } \\
\hline & 2D Sketch (0.466) & 2D Technical Drawing (0.333) & 2D Presentation (0.200) \\
\hline MF1 & 0.360 & 0.300 & 0.275 \\
MF2 & 0.280 & 0.266 & 0.172 \\
BF1 & 0.160 & 0.200 & 0.310 \\
BF2 & 0.200 & 0.233 & 0.241 \\
\hline
\end{tabular}


Table 10. The "Design Evalution Sub-Phase" of new product impact value $(W)$ alternative vehicles.

\begin{tabular}{lcccc}
\hline \multicolumn{5}{c}{ Design Evolution Phase (0.330) } \\
\hline & 3D Clay Model (0.375) & 3D DT \& CNC (0.208) & $\begin{array}{c}\text { 3D CAD Model } \\
(0.291)\end{array}$ & $\begin{array}{c}\text { 3D CAD Detail Trim } \\
(0.125)\end{array}$ \\
\hline MF1 & 0.333 & 0.185 & 0.473 & 0.100 \\
MF2 & 0.148 & 0.185 & 0.315 & 0.200 \\
BF1 & 0.296 & 0.296 & 0.157 & 0.450 \\
BF2 & 0.222 & 0.333 & 0.052 & 0.250 \\
\hline
\end{tabular}

Table 11. The "Design Verification Sub-Phase" of new product impact value $(W)$ alternative vehicles.

\begin{tabular}{ccccc}
\hline \multicolumn{5}{c}{ Design Verification Phase (0.204) } \\
\hline & $\begin{array}{c}\text { 3D Rapid } \\
\text { Prototype (0.427) }\end{array}$ & $\begin{array}{c}\text { 3D Functional } \\
\text { Prototype (0.353) }\end{array}$ & $\begin{array}{c}\text { 3D Production } \\
\text { Assembly (0.158) }\end{array}$ & $\begin{array}{c}\text { 3D Data Transfer } \\
(0.061)\end{array}$ \\
\hline MF1 & 0.148 & 0.136 & 0.428 & 0.296 \\
MF2 & 0.222 & 0.136 & 0.333 & 0.148 \\
BF1 & 0.333 & 0.318 & 0.190 & 0.333 \\
BF2 & 0.296 & 0.409 & 0.047 & 0.222 \\
\hline
\end{tabular}

Table 12. The "Vehicle Design Main-Phase" of new product impact value $(W)$ alternative firms.

\begin{tabular}{lcccc}
\hline & $\begin{array}{c}\text { Design Creation Phase } \\
(0.466)\end{array}$ & $\begin{array}{c}\text { Design Evolution Phase } \\
(0.330)\end{array}$ & $\begin{array}{c}\text { Design Verification Phase } \\
(0.204)\end{array}$ & $W$ \\
\hline MF1 & 0.322 & 0.313 & 0.196 & 0.293 \\
MF2 & 0.253 & 0.210 & 0.204 & 0.228 \\
BF1 & 0.203 & 0.274 & 0.304 & 0.247 \\
BF2 & 0.218 & 0.198 & 0.291 & 0.226 \\
\hline
\end{tabular}

Table 13. AHP maths formula that creates the model structure [15].

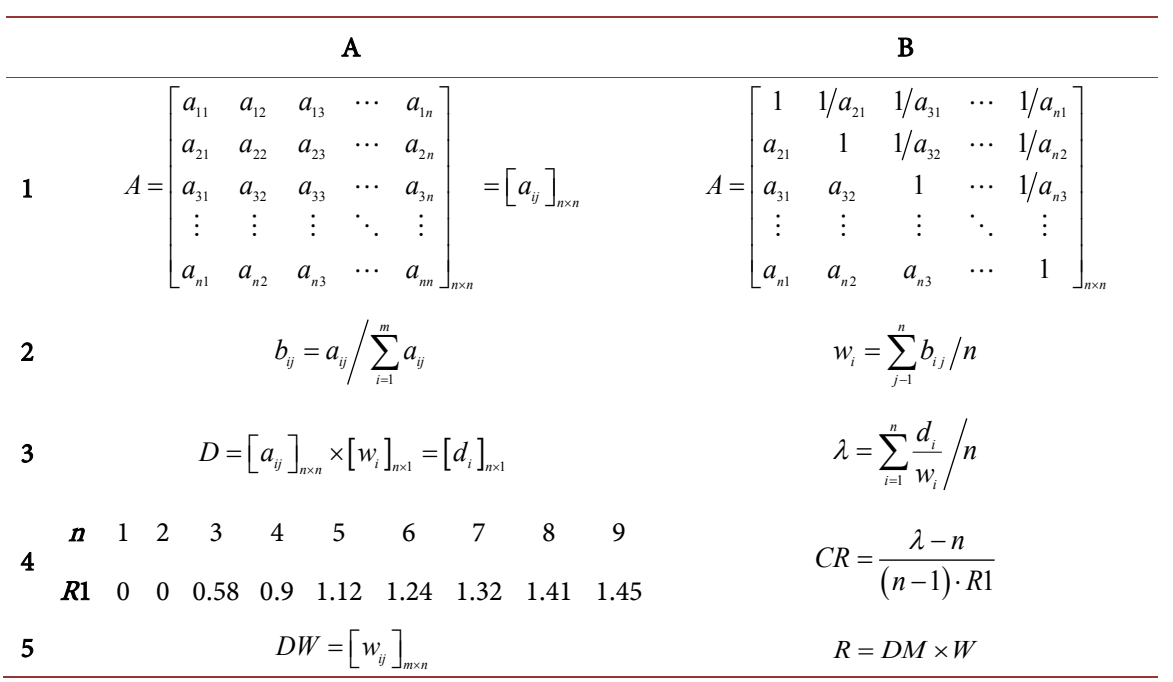


based on feedback, under binary comparison method calculated [14] [15] [27] [44] [45] [46] [47]. Analytic hierarchy method in the determination of factors creates the next phase vector dominance. The vector of variables " $n \times 1$ " level superiority is calculated with the expression " $W=\left[w_{i}\right]_{n \times 1}$ ". Among the factors defined in question the severity of " $i=1,2,3, \cdots, n$ and $j=1,2,3, \cdots, n$ " in the formula for the vector " $W=\left[w_{i}\right]_{n \times 1}$ " to expose must be calculated horizontally under. Therefore, " $W$ " forming a horizontal vector equality status Table 13, 2A column transmitted " $b_{i j}$ " matrix values. The reciprocal of the arithmetic mean of the elements of this matrix row equality are given in Table 13, $2 \mathrm{~B}$ the formula column. In addition, background this formula the percentage significance of factors distribution vector rate [14] [15] [27] [44] [45] [46] [47]. Analytic hierarchy math method in calculation of the consistency model of the third stage gate vector dominance. Factors " $i=1,2,3, \cdots, n$ and $j=1,2,3, \cdots, n$ " expression vector of each advantage in validating the consistency check rate $(\mathrm{CR})$ for the value of 0.1 as a result less than or equal to from. In access to achieve consistent $\mathrm{CR}$ value first A matrix equal the biggest attribute of Table 13, $2 \mathrm{~B}$ is calculated under the formula " $\lambda$ " contained in the column. Saaty (1980), for each other matrix, artificial use of the random variable size " $n$ ", consistency check rate (CI) is calculated with relative random index (RI) with value (Table 13: $4 \mathrm{~A}$ column) [14]. Therefore, CI dividing the number of, RI times the undermentioned situations (Table 13) from the given equality $4 \mathrm{~B}$ in column; by utilizing $\mathrm{CR}$ range is verified. In addition, the CR ratio: other matrix relative consistency checks between the indices of the matrix value comparison of the parts contained in the whole, resulting from a measure of harmony. The ratio of the value of the aforementioned, CR rate 0.1 small in the hierarchy structure refers to the level of acceptable inconsistency. AHP mathematical model in this value is larger amounts than the $\mathrm{CR}$ rate, establishing the structure, creating a phase of the decision makers to compare recurrence (Table 13: 4B column). AHP, evaluation on the results of the fourth or final consecutive structure and obtaining the community. AHP mathematical model all the first three stages under the hierarchy model for calculation. This is the last step in the hierarchy structure creates each of " $n$ " criteria " $m \times 1$ " size by creating the advantages of horizontal vectors " $m \times n$ " level "DW" decision matrix stands out occurred. Therefore, the computed matrix criteria as a result of the product of the " $W$ " vector of supremacy between Table 13 , under the $5 \mathrm{~A}$ column vector given equality with $5 \mathrm{~B}$ column value of " $R$ " [14] [15] [27] [44] [45] [46] [47].

The lower level phases of " $R$ " effective rate $=\Sigma$ fundamental stage " $W$ " significance (Table 13: 5A column).

The rate of a sub-affects the fundamentals of alternative criteria are attached to the underlying " $R$ " the significance (Table 13:5B column) of this lower level phase effect rate " $R$ " $=W \times[$ (alternative automotive companies use value the significance of the lower level sub-stage of the fundamental phase " $W$ " $\times$ values "R" effect rate $)+(\ldots \ldots .)+.(\ldots \ldots . .)+.(\ldots \ldots .)$.$] .$ 
Table 14. Values of vehicle design stages affecting the new product (EC view).

\begin{tabular}{|c|c|c|c|}
\hline \multicolumn{2}{|r|}{ Vehicle Design Process } & \multicolumn{2}{|c|}{ Alternative Automotive Vehicles } \\
\hline $21.7 \%$ & 2D Sketch Phase & $29.5 \%$ & MF1 \\
\hline $15.5 \%$ & 2D Technical Drawing Phase & $22.9 \%$ & MF2 \\
\hline $9.4 \%$ & 2D Presentation Phase & $24.8 \%$ & BF1 \\
\hline $12.4 \%$ & 3D Clay Model Phase & $22.7 \%$ & BF2 \\
\hline $6.9 \%$ & 3D DT\&CNC Phase & & \\
\hline $9.6 \%$ & 3D CAD Model Phase & & \\
\hline $4.1 \%$ & 3D CAD Detail Trim Phase & & \\
\hline $8.7 \%$ & 3D Rapid Prototype Phase & & \\
\hline $7.2 \%$ & 3D Functional Prototype Phase & & \\
\hline $3.2 \%$ & 3D Production Assembly Phase & & \\
\hline $1.2 \%$ & 3D Data Control and Transfer Phase & & \\
\hline
\end{tabular}

The calculation of vehicle design stage in automotive companies MF1 (Table 13: 5Bcolumn, AHP calculation example):

" $R$ " effective rate $=0.330[(0.375 \times 0.333)+(0.208 \times 0.185)+(0.291 \times 0.473)$ $+(0.125 \times 0.100)]+0.204[(0.427 \times 0.148)+(0.353 \times 0.136)+(0.158 \times 0.428)+$ $(0.061 \times 0.296)]+0.466[(0.466 \times 0.360)+(0.333 \times 0.300)+(0.200 \times 0.275)]=$ 0.293

Sub-stages alternative automotive companies use to calculate values for: alternative use value and lower automotive companies vehicles of the sub-stages with the main-phase of collecting the sum of the values of significance " $W$ " results (Table 13: 5B column). Therefore, Table 13 calculation method and the selection values for each other alternative automotive company " $R$ " impact effective rate [14] [15] [27] [44] [45] [46] [47].

\section{Conclusion and Recommendations}

In this study, the effect of the design activities on the final product, which is 
composed of 11 sub-stages, which are under the basic steps, has been analysed in the automotive industry companies within the scope of application, concept development phase, concept testing phase and concept formation phase (Table 14). In addition, the 3 main and 11 sub-vehicle design phases used by the competing automotive companies were identified and the impact of these processes on the final product was evaluated. Analytical hierarchy method was used in the evaluation studies and the results were tested with EC software.

As a result of the analysis, the impact significance value at the firm level for each vehicle design phase is given in Table 14. The automotive company which has the most effective use with the ratio of 0.295 is the MF1. Following MF1 automotive company, BF1 vehicle industry with a value of 0.247 is located. MF2, $\mathrm{BF} 2$, automotive companies were found to be in third and fourth rank with close to one another, with the results of 0.228 and 0.226 (Table 14). Vehicle design activities in the automotive industry constitute the process of development process in which multiple stages of high variability are evaluated simultaneously. With the development of new products, regarding to the automotive companies who are under heavy competition, this situation creates great pressure in the management level where the time is valuable. This choice is the first and most important step in determining the phase definitions for analysis. The decision to form a new product development process fits best for automotive company criteria and is an important prerequisite for efficient use of own resources (Table 14). The efficient use of resources is also of great importance in terms of the continuity and competitiveness of the enterprise. The analytic hierarchy method exemplified by this study provides great convenience to the firm's senior management and enables the creation, updating and new process editing fast, effective and accurate.

\section{Conflicts of Interest}

The authors declare no conflicts of interest regarding the publication of this paper.

\section{References}

[1] Carter, C.R. and Easton, P.L. (2015) Sustainable Supply Chain Management: Evolution and Future Directions. International Journal of Physical Distribution \& Logis tics Management, 41, 46-62. https://doi.org/10.1108/09600031111101420

[2] Wynn, D.C., Caldwell, N.H.M. and Clarkson, P. (2014) Predicting Change Propagation in Complex Design Workflows. Journal of Mechanical Design, 136, 81-90. https://doi.org/10.1115/1.4027495

[3] Königs, S.F. (2014) Konzeption und Realisierung einer Methode zur templategestützten Systementwicklung. Technische Universität, Berlin, 34-75.

[4] Kumar, B. and Sarkar, P. (2016) Prediction of Future Car Forms Based on Historical trends. Engineering and Material Sciences, 8, 764-766. https://doi.org/10.1016/j.pisc.2016.06.082

[5] Viswanathan, V., Atilola, O., Esposito, N. and Linsey, J. (2014) A Study on the Role 
of Physical Models in the Mitigation of Design Fixation. Journal of Engineering Design, 25, 25-43. https://doi.org/10.1080/09544828.2014.885934

[6] Erichsen, A., Pedersen A., Steinert, M. and Welo, T. (2016) Learning in Product Development: Proposed Industry Experiment Using Reflective Prototyping. Procedia CIRP, 50, 454-459. https://doi.org/10.1016/j.procir.2016.04.142

[7] Toepfer, F. and Naumann, T. (2016) Management of Vehicle Architecture Parameters. DS 84: Proceedings of the DESIGN 2016 14th International Design Conference, Glasgow, 1679-1688.

[8] Nikander, J.B., Liikkanen, L.A. and Laakso, M. (2014) The Preference Effect in Design Concept Evaluation. Design Studies, 35, 473-499.

https://doi.org/10.1016/j.destud.2014.02.006

[9] Ström, M., Raudberget, D. and Gustafsson, G. (2016) Instant Set Based Design, an Easy Path to Set-Based Design. Procedia CIRP, 50, 234-239.

[10] Atilola, O., Tomko, M. and Linsey, J.S. (2016) The Effects of Representation on Idea Generation and Design Fixation: A Study Comparing Sketches and Function Trees. Design Studies, 42, 110-136. https://doi.org/10.1016/j.destud.2015.10.005

[11] Moreno, D.P., Yang, M.C., Hernández, A.A., Linsey, J.S. and Wood, K.L. (2016) Design Computing and Cognition. Vol. 14, Springer, Berlin, 607-624. https://doi.org/10.1007/978-3-319-14956-1

[12] Ward, A.C. and Sobek, D.K. (2014) Lean Product and Process Development. Lean Enterprise Institute Press, Cambridge.

[13] Kennedy, B.M., Sobek, D.K. and Kennedy, M.N. (2014) Reducing Rework by Applying Set-Based Practices Early in the Systems Engineering Process. Systems Engineering, 17, 278-296. https://doi.org/10.1002/sys.21269

[14] Saaty, T. (1980) The Analytic Hierarchy Process. Mc-Graw-Hill, New York.

[15] Saaty, T. and Vargas, L. (2012) Models, Methods, Concepts and Applications of the Analytic Hierarchy Process. 2nd Edition, Springer, New York.

https://doi.org/10.1007/978-1-4614-3597-6

[16] Liu, A., Liu, H., Xiao, Y. and Tsai, S. (2018) An Empirical Study on Design Partner Selection in Green Product Collaboration Design. Sustainability, 10, 133.

[17] Yang, G.D., Yang, Y., Zhang, X. and Aijun, L. (2015) Multi-Objective Dynamic Fuzzy Scheduling and Its Algorithm in Product Collaborative Design Considering Emergency. Journal of Intelligent \& Fuzzy Systems, 29, 1355-1365. https://doi.org/10.3233/IFS-141491

[18] Xing, Q.S., Yang, Y., Liu, A.J. and Guo, D.Y. (2014) Coordination Efficiency Considered Accident in Product Collaborative Design Task. Systems Engineering-Theory \& Practice, 34, 1043-1051.

[19] Dain, L., Calvi, R. and Cheriti, S. (2011) Measuring Supplier Performance in Collaborative Design: Proposition of a Framework. Research and Development Manager, 41, 61-79.

[20] Park, J.H. and Seo, K. (2006) A Knowledge-Based Approximate Life Cycle Assessment System for Evaluating Environmental Impacts of Product Design Alternatives in a Collaborative Design Environment. Advanced Engineering Informatics, 20, 147-154. https://doi.org/10.1016/j.aei.2005.09.003

[21] Zhu, W. and He, Y. (2017) Green Product Design in Supply Chains under Competition. European Journal of Operational Research, 258, 165-180. https://doi.org/10.1016/j.ejor.2016.08.053

[22] Yang, K., Wu, S. and Zhou, L. (2016) A Conflict Detection Model Based on Con- 
straint Satisfaction in Food Product Collaborative Design. Advance Journal of Food Science and Technology, 10, 37-42. https://doi.org/10.19026/ajfst.10.1749

[23] Zavadskas, E.K., Antucheviciene, J., Turskis, Z. and Adeli, H. (2016) Hybrid Multiple Criteria Decision Making Methods: A Review of Applications in Engineering. Scientia Iranica, 23, 1-20.

[24] Wan, S.P., Xu, G.L. and Dong, J.Y. (2017) Supplier Selection Using ANP and ELECTRE II in Interval 2-Tuple Linguistic Environment. Information Sciences, 385, 19-38. https://doi.org/10.1016/j.ins.2016.12.032

[25] Mardani, A., Jusoh, A., Nor, K.M., Khalifah, Z., Zakwan, N. and Valipour, A. (2015) Multiple Criteria Decision Making Techniques and Their Applications A Review of the Literature from 2000 to 2014. Economic Research-Ekonomska Istraživanja, 28, 516-571.

[26] Hashemi, S.H., Karimi, A. and Tavana, M. (2015) An Integrated Green Supplier Selection Approach with Analytic Network Process and Improved Grey Relational Analysis. International Journal of Production Economics, 159, 178-191. https://doi.org/10.1016/j.ijpe.2014.09.027

[27] Ömürbek, N. and Şimşek, A. (2014) Analitikhiyerarşisüreciveanalitikağsüreciyöntemleriile online alışveriş site seçimi. Yönetimve Ekonomi Araştırmalari Dergisi, 22, 306-327.

[28] Cheng, Y., He, F., Wu, Y. and Zhang, D. (2016) Meta Operation Conflict Resolution for Human-Human Interaction in Collaborative Feature Based CAD Systems. Cluster Computing, 19, 237-253. https://doi.org/10.1007/s10586-016-0538-0

[29] Hepworth, A., Tew, K., Trent, M., Ricks, D., Jensen, C.G. and Red, W.E. (2014) Model Consistency and Conflict Resolution with Data Preservation in Multi-User Computer Aided Design. Journal of Computing and Information Science in Engineering, 14, 21-28. https://doi.org/10.1115/1.4026553

[30] Zhu, J. and Song, X.D. (2012) A Conflict Detection Algorithm Based on the Design History in Collaborative CAD Design. Computer \& Digital Engineering, 5, 79-81.

[31] Sivilevicius, H. and Maskeliünaite, L. (2018) Multiple Criteria Evaluation and the Inverse Hierarchy Model for Justifying the Choice of Rail Transport Mode. Promet-Traffic \& Transportation, 30, 57-60. https://doi.org/10.7307/ptt.v30i1.2417

[32] Aşchilean, I., et al. (2017) Choosing the Optimal Technology to Rehabilitate the Pipes in Water Distribution Systems Using the AHP Method. Energy Procedia, 112, 19-26. https://doi.org/10.1016/j.egypro.2017.03.1109

[33] Naghiu, G.S., Giurca, I., Aşchilean, I. and Badea, G. (2016) Multicriterial Analysis on Selecting Solar Radiation Concentration Ration for Photovoltaic Panels Using Electre Method. Procedia Technology, 22, 773-780. https://doi.org/10.1016/j.protcy.2016.01.048

[34] Zavadskas, E.K. and Podvezko, V. (2016) Integrated Determination of Objective Criteria Weights in MCDM. International Journal of Information Technology \& Decision Making, 15, 267-283. https://doi.org/10.1142/S0219622016500036

[35] Succurro, M. and Costanzo, G.D. (2016) Finance and R\&D Investment: A Panel Study of Italian Manufacturing Firms. International Journal of Economics and Finance, 8, 95-110. https://doi.org/10.5539/ijef.v8n8p95

[36] Sakthivel, G., Ilangkumaran, M. and Gaikwad, A. (2015) A Hybrid Multi-Criteria Decisionmodeling Approach for the Best Biodiesel Blend Selection Based on ANPTOPSIS Analysis. Ain Shams Engineering Journal, 6, 239-256. https://doi.org/10.1016/j.asej.2014.08.003 
[37] Liu, A., Hu, H., Zhang, X. and Lei, D. (2017) Novel Two-Phase Approach for Process Optimization of Customer Collaborative Design Based on Fuzzy-QFD and DSM. IEEE Transactions on Engineering Management, 64, 193-207. https://doi.org/10.1109/TEM.2017.2651052

[38] Kesten, A.S. and Öğüt, K.S. (2014) A New Passenger Oriented Performance Measurement Framework for Public Rail Transportation Systems. Promet-Traffic \& Transportation, 26, 299-311.

[39] Chemweno, P., Pintelon, L., Van Horenbeek, A. and Muchiri, P. (2015) Development of a Risk Assessment Selection Methodology for Asset Maintenance Decision Making: An Analytic Network Process (ANP) Approach. International Journal of Production Economics, 170, 663-676. https://doi.org/10.1016/j.ijpe.2015.03.017

[40] Türk, S., Özcan, E. and John, R. (2017) Multiobjective Optimisation in Inventory Planning with Supplier Selection. Expert Systems with Applications, 78, 51-63. https://doi.org/10.1016/j.eswa.2017.02.014

[41] You, X.Y., You, J.X., Liu, H.C. and Zhen, L. (2015) Group Multi-Criteria Supplier Selection Using an Extended VIKOR Method with Interval 2 Tuple Linguistic Information. Expert Systems with Applications, 42, 1906-1916.

https://doi.org/10.1016/j.eswa.2014.10.004

[42] Freeman, J. and Chen, T. (2015) Green Supplier Selection Using an AHP-EntropyTOPSIS Framework. Supply Chain Management. An International Journal, 20, 327-340. https://doi.org/10.1108/SCM-04-2014-0142

[43] Bhattacharya, A., Mohapatra, P., Kumar, V., et al. (2014) Green Supply Chain Performance Measurement Using Fuzzy ANP-Based Balanced Scorecard: A Collaborative Decision-Making Approach. Production Planning \& Control, 25, 698-714. https://doi.org/10.1080/09537287.2013.798088

[44] Tütek, H., Gümüşoğlu, Ş. and Özdemir, A. (2012) Sayisal Yöntemler Yönetsel Yaklaşim. Beta Basim Yayim, Baski, İstanbul, 71-349.

[45] Aksoy, E., Ömürbek, N. and Karaatli, M.(2015) AHP Temelli MULTIMOORA ve COPRAS Yöntemi İle Türkiye Kömür İşletmeleri’nin Performans Değerlemesi. Vol. 33. Hacettepe Üniversitesi İktisadi ve İdari Bilimler Fakültesi Dergisi, Ankara, 11-14.

[46] Kundakçı, N. and Işık, A.T. (2016) Integration of MACBET and COPRAS Methods to Select Air Compressor for a Textile Company. Decision Science Letters, 5, 5.

[47] Tunca, Z., Ömürbek, N., Cömert, G. and Aksoy, E. (2016) Opec Ülkelerinin Performanslarının Çok Kriterli Karar Verme Yöntemlerinden Entropi ve Maut İle Değerlendirilmesi. Vol. 7, Süleyman Demirel Üniversitesi Vizyoner Dergisi, Isparta, 4-5. 